\title{
Evaluation of Intrauterine Adhesion After Hysteroscopic Resection of Uterine Septum
}

\author{
Leili Hafizi $^{\circledR}$, Maliheh Amirian², Seyedeh Azam Pourhoseini', Akram Behrouznia ${ }^{1}$, Mina Baradaran ${ }^{*}$
}

\begin{abstract}
Objectives: The aim of this study was to evaluate the rate and severity of intrauterine adhesions (IUAs) and their association with septum morphology following the hysteroscopic resection of the uterine septum.

Materials and Methods: This cross-sectional study was conducted on patients with septate uteri undergoing hysteroscopic septolysis with scissors. Two months after the surgery, the second look hysteroscopy was performed and the intrauterine cavity was evaluated for IUAs and residual septum. Afterward, the rate and severity of adhesions and residual septum and their association with the septal morphology were studied as well.

Results: In general, 30 patients were entered into the study. The incidence rate of adhesions following septoplasty was $23.3 \%$. It was mild and moderate in $16.7 \%$ and $6.7 \%$, respectively. The incidence rate of adhesions was not related to the length and width of the septum $(P=0.281, P=0.495)$. The rate of the residual septum in second-look hysteroscopy was $56.7 \%$, which was less than $0.5 \mathrm{~cm}$ in most cases (33.3\%). It was not more than $1 \mathrm{~cm}$ in any case. The possibility of the residual septum was significantly higher in long septa $(P=0.045)$ whereas it was not related to the septum width $(P=0.087)$.

Conclusions: IUA following hysteroscopic septolysis is a possibility, especially in infertile patients which is often mild. The presence of a uterine factor in such patients may justify the risk of increased IUAs in our study in comparison to others. Therefore, it is able to perform second-look hysteroscopy in infertile patients with a septate uterus for the diagnosis and early treatment of IUAs.

Keywords: Uterine septum, Septoplasty, Metroplasty, Hysteroscopy, Intrauterine adhesion, Synechia
\end{abstract}

\section{Introduction}

Uterine abnormalities, which are generally referred to as Müllerian anomalies, are the cause of many fertility failures (1-4). Among such anomalies, the septate uterus (SU) accounts for $12 \%$ of cases (1). In such cases, a septum divides the inner portion of the uterus at its middle. Regarding outcomes such as infertility, abortion, and labour complications such as preterm labor and the abnormal placement of the fetus during labour, SU has further attracted the attention of researchers. Nevertheless, some women with the US mention no fertility-related problems (1-4). The treatment of choice for $S U$ is surgical resection, which was initially done through open abdominal surgery.

However, with recent advances, the hysteroscopic surgical method has been introduced as the standard surgical method for SU $(1,3)$ since it is a simple technique with low complications. In recent years, even hysteroscopic metroplasty in the office has been welcomed by doctors and patients for short uterine septa (5). Taken together, hysteroscopic metroplasty has resulted in more favorable fertility outcomes (6-13). Even the performance of repeated metroplasty in cases with a residual uterine septum following primary septoplasty has led to better fertility outcomes (5).
Despite the limited number of studies, the occurrence of intrauterine adhesions (IUAs) following the hysteroscopic metroplasty of SU has been reported as a rare complication (1). Prior research considers IUA as a likely possibility following all types of intrauterine invasive interventions (14) in addition to introducing hysteroscopy as the best diagnostic and therapeutic option for IUA (15-19).

Considering the small number of research on the risk of IUA following hysteroscopic septolysis, performing a research project seems necessary in this respect. The current study aimed to evaluate the rate and severity of IUAs and their association with septum morphology following the hysteroscopic resection of the uterine septum.

\section{Materials and Methods \\ In this cross-sectional study, patients, who were candidates for septum resection, were recruited during 2015-2016. The study protocol was described to all cases having fulfilled the inclusion criteria, and an informed consent form was obtained from each participant. The SU was diagnosed based on hysterosalpingography, magnetic resonance imaging, or sonohysterosalpingography. The demographic characteristics of the patients were recorded in a designed questionnaire. Hysteroscopic septolysis}




\section{Key Messages}

- Uterine septum among uterine anomalies is a relatively common anomaly and can be accompanied by pregnancy complications.

- Hysteroscopic surgery is a low-risk operation, and significantly reduces pregnancy complications

was performed by a single surgeon, a fellowship of gynecological laparoscopy, with the Olympus laparoscope and hysteroscope in the gynecology operation theater of Imam Reza hospital.

Before hysteroscopy, diagnostic laparoscopy was done to definitely distinguish a septate uterus from a bicornate uterus or other possible anomalies and to perform hysteroscopic septolysis using laparoscopy to decrease the risk of uterine perforation during surgery. The patient was excluded from the study in case that diagnosing other types of uterine anomalies such as bicornate or didelphys uterus during laparoscopy. Moreover, the patient was excluded in the case of the simultaneous existence of a polyp or submucosal myoma or Asherman's syndrome, along with a uterine septum during laparoscopy.

The uterine septum was evaluated regarding its length and width and then it was removed with normal saline media using hysteroscopy scissors. Septa extending from one ostium to another one was regarded as wide. Additionally, the hysteroscope was graded from its tip in order to measure the septal length. Considering the normal length of the uterus (from the fundus to the end of the cervix), the normal cervical length, and the normal length of the uterus cavity as 7-8, 3-4, and 4-5 $\mathrm{cm}$, respectively, septa with $\leq 2 \mathrm{~cm}$ length and those over $2 \mathrm{~cm}$ were considered as short and long, respectively. The patients' data were recorded in the individual sections of the questionnaire based on the septa's length and width. After the surgery, no estrogen was prescribed and no intrauterine catheterization was done for any patient. The patients were asked to return for second-look hysteroscopy in the follicular phase after 2 months. Those patients not visiting the clinic for repeated hysteroscopy were excluded from the study. In the second-look hysteroscopy, cases such as residual septa and IUAs and their severity were evaluated, and the residual septa or adhesions were removed in case of incidence. The adhesion severity was determined based on the hysteroscopic evidence (Table 1).

The rate of residual septa, along with the presence of adhesions and their severity (mild, moderate, or severe) was recorded in the questionnaire. In addition, the association between the incidence of adhesions and their severity with the length (short or long) and width (wide or narrow) of the removed septas was determined by statistical analysis. Chi-square test and the correlation coefficient were used for data comparison. Fisher's exact test was employed to compare the quantitative data in two or more groups of qualitative variables. SPSS (version 16) was applied for statistical analyses, and the significance level was set at $P<0.05$.

\section{Results}

In general, 30 patients were entered in the study. The patients' mean age was $28.83 \pm 5.54$ years. The demographic data of the patients including age, chief complaint, previous pregnancy outcomes, and the prevalence of septal morphology (length and width) are presented in Table 2.

Based on the results, $18(60 \%)$ cases had primary infertility with no history of previous pregnancy. The other $12(40 \%)$ patients with a history of previous pregnancy had between 1 pregnancy and 6 unsuccessful pregnancies with no living child.

The total number of pregnancies was 31 cases in these 12 patients from which $29(93.55 \%)$ and $2(6.45 \%)$ cases were miscarriage and fetal death after 20 weeks of gestation due to premature labour, respectively. Therefore, $100 \%$ of previous pregnancies in our patients were unsuccessful.

Table 3 presents the prevalence rate of IUA in such

Table 2. Demographic Data and Morphological Prevalence of Uterine Septum

\begin{tabular}{llll}
\hline Parameter & Criteria & Number (\%) & Total (\%) \\
\hline \multirow{2}{*}{ Age (year) } & $<30$ & $17(56.7)$ & \\
& $30-40$ & $12(40)$ & $30(100)$ \\
& $>40$ & $1(3.3)$ & \\
& Primary infertility & $18(60)$ & \\
Symptom & Secondary infertility & $3(10)$ & $30(100)$ \\
& Recurrent abortion & $7(23.3)$ & \\
Outcome & Fetal death & $2(6.7)$ & \\
of previous & Abortion & $29(93.55)$ & \\
pregnancies & Fetal death & $2(6.45)$ & \\
& Live birth & $0(0)$ & $30(100)$ \\
Septum length & Long & $22(73.3)$ & \\
& Short & $8(26.7)$ & $30(100)$ \\
Septum width & Wide & $26(86.7)$ & \\
& Narrow & $4(13.3)$ & \\
\hline
\end{tabular}

Table 1. Adhesion Severity According to Hysteroscopic Evidence

\begin{tabular}{ll}
\hline Classification & Condition \\
\hline Mild & Filmy adhesions composed of basalis endometrial tissues causing partial uterine cavity occlusion \\
Moderate & $\begin{array}{l}\text { Characteristically thick and still covered with endometrium that may bleed upon division, partially or totally occluding the } \\
\text { uterine cavity }\end{array}$ \\
Severe & $\begin{array}{l}\text { Adhesions only composed of the connective tissue, lacking any endometrial lining, and not likely to bleed upon division. These } \\
\text { adhesions may partially or totally occlude the uterine cavity }\end{array}$ \\
\hline
\end{tabular}


patients in the hysteroscopic study performed 2 months after the initial surgery. Adhesion was recorded in 7 (23.4\%) patients. It was mild in most cases $(n=5,71.43 \%)$ while severe adhesions were not found in any patient. The association between septum length and width by the incidence of IUA after hysteroscopic septolysis is provided in Table 4.

No statistically significant correlation was found with regard to the association between the septal length and the IUA incidence following septoplasty $(P=0.377)$. The same result was obtained for the septal width $(P=0.548)$ although no adhesion was observed in 4 cases with a narrow septum.

Table 5 summarizes data regarding the association between the septal length and width and the uterine adhesion severity after hysteroscopic septolysis. Accordingly, no significant association was found in this respect $(P=0.281, P=0.495)$.

Table 3. The Frequency of Intrauterine Adhesion Incidence and its Severity After Hysteroscopic Septoplasty $(n=30)$

\begin{tabular}{ll}
\hline Adhesion Rate & No. $(\%)$ \\
\hline Without adhesion & $23(76.6)$ \\
With adhesion & \\
Mild & $5(16.7)$ \\
Moderate & $2(6.7)$ \\
\hline
\end{tabular}

Table 4. The Correlation Between Septum Length and Width With Intrauterine Adhesion Incidence After Hysteroscopic Septoplasty

\begin{tabular}{llccc}
\hline \multirow{2}{*}{ Parameter } & & \multicolumn{2}{c}{ Adhesion, No. (\%) } & \multirow{2}{*}{$\boldsymbol{P}$ Value $^{\mathbf{a}}$} \\
\cline { 3 - 4 } & & No & Yes & \\
\hline \multirow{2}{*}{ Septum length } & Long & $16(72.7)$ & $6(27.3)$ & \multirow{2}{*}{0.377} \\
& Short & $7(87.5)$ & $1(12.5)$ & \\
\multirow{2}{*}{ Septum width } & Wide & $19(73.1)$ & $7(26.9)$ & \multirow{2}{*}{0.548} \\
& Narrow & $4(100)$ & $0(0)$ & \\
\hline a Fisher exact test. & & & &
\end{tabular}

In the hysteroscopy performed 2 months after septoplasty, the residual septum was detected in 17 (56.7\%) patients and was $0.5 \mathrm{~cm}$ and $1 \mathrm{~cm}$ in $10(33.3 \%)$ and 7 (23.3\%) cases, respectively. The residual septum was not more than $(\max ) 1 \mathrm{~cm}$ in any case.

Table 6 provides the relationship between the septal length and width and the residual septum after hysteroscopic septolysis.

A significant relationship was found for the septal length $(P=0.045)$, indicating that the possibility of the residual septum is higher in long septa rather than short ones. Finally, no significant association was observed for the septum width in this respect $(P=0.087)$.

\section{Discussion}

In the present study, among the 31 studied pregnancies, no case of live birth was found in $40 \%$ of patients with a previous gestation. In addition, $60 \%, 10 \%$, and $33.3 \%$ of cases had primary infertility, secondary infertility, and a history of abortion, respectively, whereas $6.7 \%$ of them had a history of fetal death in the 2 nd half of their gestation. The abortion rate and the fetal death rate were $93.55 \%$ and $6.45 \%$, respectively. The reason for the difference, in our statistics in comparison to other studies, is probably due to the referral system of our center.

Heinonen reported the coexistence of SU with a reduced fetal survival rate (6). In the study by Hua et al (20), labor complications which accompany uterine abnormalities included the breech presentation of the fetus (25\%-30\%), oblique and transverse presentation (5\%), and preterm labor $(20 \%)$. When compared to similar studies regarding pregnancy outcomes, the higher rate of infertility among our patients is probably because Milad Infertility Center, affiliated to Mashhad University of Medical Sciences, is one of the main centers which refers patients to Imam Reza hospital.

In the study by Bettocchi et al, hysteroscopic septolysis

Table 5. The Correlation Between Septal Length and Width With Intrauterine Adhesion Severity After Hysteroscopic Septoplasty

\begin{tabular}{|c|c|c|c|c|c|c|}
\hline \multirow{2}{*}{ Parameter } & & \multicolumn{3}{|c|}{ Adhesion Severity, No. (\%) } & \multirow{2}{*}{ Total, No. $(\%)$} & \multirow{2}{*}{$P$ Value $^{\mathrm{a}}$} \\
\hline & & No & Mild & Moderate & & \\
\hline \multirow{2}{*}{ Septum length } & Long & $16(72.7)$ & $5(22.7)$ & $1(4.5)$ & \multirow{2}{*}{$30(100)$} & \multirow{2}{*}{0.281} \\
\hline & Short & $7(87.5)$ & $0(0)$ & $1(12.5)$ & & \\
\hline \multirow{2}{*}{ Septum width } & Wide & $19(73.1)$ & $5(19.2)$ & $2(7.7)$ & \multirow{2}{*}{$30(100)$} & \multirow{2}{*}{0.495} \\
\hline & Narrow & $4(100)$ & $0(0)$ & $0(0)$ & & \\
\hline
\end{tabular}

a Fisher exact test.

Table 6. The Correlation Between Septal Length and Width With Residual Septum After Hysteroscopic Septoplasty

\begin{tabular}{llccr}
\hline \multirow{2}{*}{ Parameter } & & \multicolumn{2}{c}{ Residual Septum } & \multirow{2}{*}{ Total, No. (\%) } \\
\cline { 3 - 4 } Septum length & Long & $7(31.8)$ & $15(68.2)$ & $30(100)$ \\
& Short & $6(75)$ & $2(25)$ & 0.045 \\
\multirow{2}{*}{ Septum width } & Wide & $13(50)$ & $13(50)$ & $30(100)$ \\
& Narrow & $0(0)$ & $4(100)$ & 0.087 \\
\hline
\end{tabular}

a Fisher exact test. 
with scissors was successful in $93.1 \%$ of cases of SU $(\mathrm{N}=260)$, resulting in no residual septum. The highest rate of residual septa was observed in patients with a long septum whereas most of such septa were also wide (5). In our study, more residual septums were found in long septa compared to short ones. The reason for a large amount of the residual septum in our study may be due to the use of scissors and the perioperative bleeding. Moreover, despite the programmed operation for the follicular phase, there was not proper visibility for complete removal of the septum in the fundus in some patients due to the irregular cycles or undesirable endometrium. Regarding long septa, which are removed by scissors, the surgical time increases by an increase in the septal width while the probability of a one-step cutting with scissors reduces and the scissors blade slows down which can be one of the etiologies for the increased residual septum in such cases. The increased surgical time in longer and wider septa can also have other outcomes such as increased bleeding and the reduced vision of the surgeon which can thus result in a higher rate of iatrogenic complications (5).

In the present study, the total adhesion rate was $23.3 \%$, which is higher than most similar studies. It could be attributed to the ethnic characteristics of our population or the higher number of infertile cases who entered the study. This could focus attention on the fact that there may be a uterine factor in infertile patients which increases the likelihood of subsequent adhesions. However, the observed IUAs were mostly filmy adhesions (71.43\%) and no case of dense adhesion was observed in this study.

Taskin et al reported one case of IUA, which was due to endometrial injury during hysteroscopy, in 15 cases of SU following hysteroscopic metroplasty with a resectoscope (21). Meanwhile, the resection of multiple submucosal fibroids, which is done by hysteroscopic surgery, has shown an extremely high risk of IUA, especially in normal uteri with no previous gestations (22). In the study by Wang et al, no case of IUA was found in any of the 190 SU undergoing surgery by a resectoscope (23). Following hysteroscopic metroplasty with scissors, Tonguc et al observed 6 (9.5\%) cases of IUA after 63 surgeries on SU in which the preventive measures had demonstrated a failure (24). The other study reported an IUA rate of up to $6.7 \%$ after septal incision (10).

At least two etiologies have been proposed for the incidence of post-hysteroscopy adhesions. First, following the increase in the surgical incision site (e.g., long and wide septa), the surgical wound is larger with a subsequently longer healing time, resulting in the accumulation of more mediators, including exudate, cytotoxins, and other primary cells which can increase the risk of IUAs (25). Furthermore, the role of cytokines such as fibroblast growth factor, platelet-derived growth factor, and transforming growth factor type 1 has been mentioned in the pathogenesis of IUA, which could be the reason for more adhesion formation after the removal of the uterine septum (21). The other reason for such adhesions could be the errors made in the applied technique for septum removal.

Although there are some cases of SU with no pregnancy complications (1-4), Green et al and Valle et al concluded that the uterine septum is associated with spontaneous and recurrent abortion up to $20-25 \%(27,28)$. These abortions usually occur at the end of the first trimester or the beginning of the second trimester due to mild labour pain and bleeding which are associated with the septal length (28). Further, the position of the fetus is more likely to be abnormal in cases with a long septate uterus (1).

In another study, Alanbay et al presented a case of recurrent large uterine fundal dehiscence consecutive to a cesarean section in a patient who had previously undergone a uterine septum resection (29). Fedele et al performed metroplastic hysteroscopic surgery on 23 patients with a short septum and 79 cases with a long septum and a history of infertility or recurrent abortions. Surgical scissors, the argon laser, and a resectoscope were was used in 80,10 , and 12 cases, respectively. The rate of pregnancy and live birth in the incomplete septum group was $89 \%$ and $75 \%$, respectively. The corresponding values were $80 \%$ and $67 \%$ in the long septum group. Therefore, no correlation was found between the success rate of the hysteroscopic metroplasty method and the septal morphology (incomplete or complete), and the septoplastic hysteroscopy results were considered successful and satisfactory (22).

\section{Conclusions}

The results of the current study brought up the risk of IUA following hysteroscopic septolysis, especially in infertile patients (accounting for most of our cases) who were mostly mild to moderate. Thus, a uterine factor may be involved in infertile women, increasing the probability of IUA after hysteroscopic septolysis. Therefore, secondlook hysteroscopy can be performed in infertile patients with an SU for the diagnosis and early treatment of IUAs.

On the other hand, in this study, the risk of the residual septum was significantly higher in long septums although the residual septum length was not $>1 \mathrm{~cm}$ in any case. Hence, second-look hysteroscopy can also be recommended after hysteroscopic septolysis in patients with a long uterine septum. One of the main limitations of the present study was the small study population and the referral of most cases from an infertility center. Therefore, further studies on a larger population of infertile patients with a uterine septum and a larger sample of women with SU are of high necessity.

\section{Authors' Contribution}

$\mathrm{LH}$ conceived of the study, did surgeries and designed the study. MA and SAP participated in the design of the study. $A B$ and $M B$ performed the statistical analysis and helped in drafting the manuscript. All authors read and approved the final manuscript. 


\section{Conflict of Interests}

The authors declare no conflict of interests.

\section{Ethical Issues}

Ethical considerations were carried out in accordance with the Stockholm Convention and approved by the Ethics Committee of Mashhad University of Medical Sciences (Ethical code No: IR.MUMS. fm.REC.1394.353).

\section{Financial Support}

The study was funded by the Research Deputy of Mashhad University of Medical Sciences.

\section{Acknowledgments}

This paper was derived from a resident's thesis for obtaining a degree in Gynecology (Under the registration number IR.MUMS.fm.REC.1394.353 and the research project code of 940607). We express our appreciation to the Vice-chancellor of Research and Women's Health Research Center of Mashhad University of Medical Sciences for their financial and material support and to all those who helped us to perform this project.

\section{References}

1. Valle RF, Ekpo GE. Hysteroscopic metroplasty for the septate uterus: review and meta-analysis. J Minim Invasive Gynecol. 2013;20(1):22-42. doi:10.1016/j.jmig.2012.09.010

2. Uterine septum: a guideline. Fertil Steril. 2016;106(3):530-540. doi:10.1016/j.fertnstert.2016.05.014

3. Homer HA, Li TC, Cooke ID. The septate uterus: a review of management and reproductive outcome. Fertil Steril. 2000;73(1):114. doi:10.1016/s0015-0282(99)00480-x

4. The American Fertility Society classifications of adnexal adhesions, distal tubal occlusion, tubal occlusion secondary to tubal ligation, tubal pregnancies, müllerian anomalies and intrauterine adhesions. Fertil Steril. 1988;49(6):944-955. doi:10.1016/s00150282(16)59942-7

5. Bettocchi S, Ceci O, Nappi L, Pontrelli G, Pinto L, Vicino M. Office hysteroscopic metroplasty: three "diagnostic criteria" to differentiate between septate and bicornuate uteri. J Minim Invasive Gynecol. 2007;14(3):324-328. doi:10.1016/j.jmig.2006.11.010

6. Heinonen PK. Reproductive performance of women with uterine anomalies after abdominal or hysteroscopic metroplasty or no surgical treatment. J Am Assoc Gynecol Laparosc. 1997;4(3):311317. doi:10.1016/s1074-3804(05)80221-x

7. Pabuçcu R, Gomel V. Reproductive outcome after hysteroscopic metroplasty in women with septate uterus and otherwise unexplained infertility. Fertil Steril. 2004;81(6):1675-1678. doi:10.1016/j.fertnstert.2003.10.035

8. Nawroth F, Schmidt T, Freise C, Foth D, Römer T. Is it possible to recommend an "optimal" postoperative management after hysteroscopic metroplasty? a retrospective study with 52 infertile patients showing a septate uterus. Acta Obstet Gynecol Scand. 2002;81(1):55-57. doi:10.1046/j.0001-6349.2001.10228.x

9. Kazer RR, Meyer K, Valle RF. Late hemorrhage after transcervical division of a uterine septum: a report of two cases. Fertil Steril. 1992;57(4):930-932. doi:10.1016/s0015-0282(16)54984-x

10. Wright $K$, Isaacson $K$. Evaluation and management of the uterine septum. In: Nezhat C, Nezhat F, Nezhat C, eds. Nezhat's VideoAssisted and Robotic-Assisted Laparoscopy and Hysteroscopy. 4th ed. New York: Cambrige University Press; 2013:86-94.

11. Esmaeilzadeh S, Agajani Delavar M, Ghanbari Andarieh M. Reproductive outcome following hysteroscopic treatment of uterine septum. Mater Sociomed. 2014;26(6):366-371. doi:10.5455/msm.2014.26.366-371
12. Agostini A, De Guibert F, Salari K, Crochet P, Bretelle F, Gamerre M. Adverse obstetric outcomes at term after hysteroscopic metroplasty. J Minim Invasive Gynecol. 2009;16(4):454-457. doi:10.1016/j.jmig.2009.03.021

13. Kormányos Z, Molnár BG, Pál A. Removal of a residual portion of a uterine septum in women of advanced reproductive age: obstetric outcome. Hum Reprod. 2006;21(4):1047-1051. doi:10.1093/ humrep/dei438

14. Asgari Z, Hafizi L, Hosseini R, Javaheri A, Rastad H. Intrauterine synechiae after myomectomy; laparotomy versus laparoscopy: Non-randomized interventional trial. Iran J Reprod Med. 2015;13(3):161-168.

15. Valle RF. Intrauterine adhesions (Asherman's syndrome). In: Marty R, Blanc B, de Montgolfier R, eds. Office and Operative Hysteroscopy. New York: Springer Verlag; 2002:229-242. doi:10.1007/978-2-8178-0841-3_30

16. Conforti A, Alviggi C, Mollo A, De Placido G, Magos A. The management of Asherman syndrome: a review of literature. Reprod Biol Endocrinol. 2013;11:118. doi:10.1186/1477-7827$11-118$

17. Yu D, Wong YM, Cheong Y, Xia E, Li TC. Asherman syndrome-one century later. Fertil Steril. 2008;89(4):759-779. doi:10.1016/j. fertnstert.2008.02.096

18. March CM. Management of Asherman's syndrome. Reprod Biomed Online. 2011;23(1):63-76. doi:10.1016/j.rbmo.2010.11.018

19. Schenker JG, Margalioth EJ. Intrauterine adhesions: an updated appraisal. Fertil Steril. 1982;37(5):593-610. doi:10.1016/s00150282(16)46268-0

20. Hua M, Odibo AO, Longman RE, Macones GA, Roehl KA, Cahill AG. Congenital uterine anomalies and adverse pregnancy outcomes. Am J Obstet Gynecol. 2011;205(6):558.e1-5. doi:10.1016/j.ajog.2011.07.022

21. Taskin O, Sadik S, Onoglu A, et al. Role of endometrial suppression on the frequency of intrauterine adhesions after resectoscopic surgery. J Am Assoc Gynecol Laparosc. 2000;7(3):351-354. doi:10.1016/s1074-3804(05)60478-1

22. Fedele L, Arcaini L, Parazzini F, Vercellini P, Di Nola G. Reproductive prognosis after hysteroscopic metroplasty in 102 women: life-table analysis. Fertil Steril. 1993;59(4):768-772. doi:10.1016/s0015-0282(16)55857-9

23. Wang S, Shi X, Hua X, Gu X, Yang D. Hysteroscopic transcervical resection of uterine septum. JSLS. 2013;17(4):517-520. doi:10.42 93/108680813×13753907291954

24. Tonguc EA, Var T, Yilmaz N, Batioglu S. Intrauterine device or estrogen treatment after hysteroscopic uterine septum resection. Int J Gynaecol Obstet. 2010;109(3):226-229. doi:10.1016/j. ijgo.2009.12.015

25. Maciver AH, McCall $M$, James Shapiro AM. Intra-abdominal adhesions: cellular mechanisms and strategies for prevention. Int J Surg. 2011;9(8):589-594. doi:10.1016/j.ijsu.2011.08.008

26. AAGL practice report: practice guidelines on intrauterine adhesions developed in collaboration with the European Society of Gynaecological Endoscopy (ESGE). Gynecol Surg. 2017;14(1):6. doi:10.1186/s10397-017-1007-3

27. Green LK, Harris RE. Uterine anomalies. Frequency of diagnosis and associated obstetric complications. Obstet Gynecol. 1976;47(4):427-429.

28. Valle RF. Clinical management of uterine factors in infertile patients. Semin Reprod Endocrinol. 1985;3(2):149-167.

29. Alanbay i, Öztürk M, Ulubay M, Keskin U, Karaşahin E. Recurrent large uterine fundal dehiscence during cesarean section after hysteroscopic uterine septum resection with uterine perforation. Case Rep Perinat Med. 2016;5(2):85-87. doi:10.1515/crpm-2015-0082

Copyright $\odot$ 2022The Author(s); This is an open-access article distributed under the terms of the Creative Commons Attribution License (http:// creativecommons.org/licenses/by/4.0), which permits unrestricted use, distribution, and reproduction in any medium, provided the original work is properly cited. 